\title{
The subjective well-being under neuroleptic scale - short version (SWN-K) and the SF-36 health survey as quality of life measures in patients with schizophrenia
}

\author{
This article was published in the following Dove Press journal: \\ Patient Preference and Adherence \\ 20 January 2012 \\ Number of times this article has been viewed
}

Jorge Mauriño'

Luis Cordero'

Javier Ballesteros ${ }^{2}$

'AstraZeneca Medical Department, Madrid, Spain; ${ }^{2}$ Department of Neuroscience-Psychiatry, University of the Basque Country, UPV/EHU, CIBERSAM, Leioa, Spain
Correspondence: J Mauriño

Serrano Galvache, 56, Parque Norte, Edificio Roble, (28033) Madrid, Spain Tel +34913019738

Fax +34913019606

Email jorgealejandro.maurino@ astrazeneca.com
Purpose: The desired outcome in schizophrenia treatment has evolved from symptom management to maximization of quality of life and functional recovery. The aim of this study was to assess the relationship between a specific well-being measure, the Subjective Well-being under Neuroleptic Scale - short version (SWN-K), and the SF-36 Health Survey as a generic quality of life measure.

Patients and methods: A multicenter, cross-sectional study was conducted with clinically stable outpatients diagnosed with schizophrenia. Spearman's rank correlation was used to assess the associations between the SWN-K total score, its five subscales, and the SF-36 domains.

Results: Ninety-seven patients were included in the study. The mean age was 35 years (standard deviation $=10$ ) and $72 \%$ were male. All correlations among domains were positive and most were statistically significant. The bodily pain domain of the SF-36 presented the lower correlations with the SWN-K (rho range 0.10-0.25), whereas the other seven domains correlated significantly (rho range $0.49-0.60$, all $P<0.001$ ). The largest correlations were obtained between the SWN-K and the SF-36 domains of general health $($ rho $=0.53)$, mental health $($ rho $=0.60)$, and vitality $($ rho $=0.54)$.

Conclusion: The positive but nevertheless moderate correlations observed between a specific well-being instrument and a generic quality of life scale supports the inclusion of diagnosisspecific tools for outcome assessment of patients with schizophrenia.

Keywords: schizophrenia, subjective well-being, quality of life, patient-reported outcomes, generic health status measures, SF-36

\section{Introduction}

In parallel to the steady improvement in treatment of patients with schizophrenia, the desired outcome has evolved from symptom management to maximization of quality of life and functional recovery. ${ }^{1}$

Generic health status measures such as the EuroQol-5D and the SF-36 Health Survey (SF-36) are increasingly being used to inform health policy. ${ }^{2,3}$ They are administered in several diseases and their use is spreading in mental health research. ${ }^{4}$ There is an increasing awareness of the need to address mental health as an integral part of improving worldwide population health. ${ }^{5}$ The self-perception of patients with severe mental disorders is a key factor in adherence, quality of life, and clinical outcome. ${ }^{6}$ However, information on the relationship between different aspects of mental health, subjective well-being, and physical health is lacking. 
The aim of this study was to assess the relationship between a specific well-being measure, the Subjective WellBeing under Neuroleptic scale - short version (SWN-K), ${ }^{7}$ and the eight domains of the public version of the SF-36 v1 as a generic quality of life measure.

\section{Material and methods}

A non-interventional, cross-sectional study was conducted in 20 mental health centers throughout Spain. The study was approved by the institutional review board of the Fundació Sant Joan de Deu (Barcelona, Spain). Written informed consent was obtained from all patients. The criteria for patient recruitment were: 18-65 years of age; a diagnosis of schizophrenia, schizoaffective disorder, or schizophreniform disorder, according to the Diagnostic and Statistical Manual of Mental Disorder: Fourth Edition; Text Revision; follow-up as an outpatient; and clinically stable as judged by the investigators.

The SWN-K is a self-rated scale consisting of 20 items with a six-point Likert response format, capturing subjective experiences of patients during antipsychotic treatment. It consists of five subscales: physical and mental functioning, self-control, emotional regulation, and social integration. Total scores range from 20 to 120 points, with higher scores indicating greater well-being. ${ }^{7,8}$ This questionnaire has been used in several studies to assess quality of life in schizophrenia from a patient's perspective. ${ }^{6,9}$

Patients completed the Spanish version of the SF-36 Health Survey, a self-reported multidimensional survey measure of health-related quality of life. ${ }^{3}$ The questionnaire contains 36 items and addresses eight health domains: physical functioning, role limitations due to physical health, bodily pain, general health perceptions, vitality, social functioning, role limitations due to emotional problems, and mental health. It can usually be completed in $5-10$ minutes. ${ }^{10}$

In addition, the investigators completed the Positive and Negative Syndrome Scale and the Clinical Global Impression - Severity Scale in order to assess the clinical status of the sample.

Demographic and clinical characteristics were described using mean, standard deviation (SD), and a 95\% confidence interval for continuous measures. Spearman's rank correlation test was used to assess associations between SWN-K total score, its five subscales, and the SF-36 domains. The SF-36 estimates were calculated using public code (SF36 v2.2.2 Stata ado, written by Philip Ryan).

\section{Results}

A total of 97 patients were included in the statistical analysis. The mean age was 35 years $(\mathrm{SD}=10)$, and males accounted for $72 \%$ of the sample. Most patients had a diagnosis of schizophrenia $(n=77)$, followed by schizoaffective disorder $(n=18)$, and schizophreniform disorder $(n=2)$. Demographic and clinical characteristics of the sample are shown in Table 1.

All correlations between domains were positive and most of them were statistically significant. As expected, the lowest correlations with the SWN-K were seen in the bodily pain domain of the SF-36 (rho range $0.10-0.25$ ). On the other hand, all other SF-36 domains significantly correlated with the SWN-K total score (rho range 0.49-0.60, all values of $P<0.001$ ). The largest correlations were recorded between the SWN-K and the SF-36 domains of general health $($ rho $=0.53)$, mental health $($ rho $=0.60)$, and vitality $($ rho $=0.54)($ Table 2$)$.

\section{Discussion}

Outcomes research in patients with schizophrenia should take into account the subjective interpretation of the mood and physical changes that are usually associated with medication intake. ${ }^{1}$ Agents involved in health technology assessment are already incorporating these other important aspects into the basic aims of discerning new treatments' efficacy and safety. ${ }^{11}$ There is published evidence on the appropriateness and accuracy of selfadministered evaluations in patients with severe chronic mental disorders. ${ }^{12-14}$ These changes will influence behavioral response to treatment and ultimately the patient's clinical outcome as mediated by their treatment compliance. ${ }^{6,15}$

Many efforts have been made to develop specific instruments to assess patients' affectation within different domains. Perception of quality of life may differ depending on the

Table I Patient demographics and clinical characteristics

\begin{tabular}{ll}
\hline & $\mathbf{N}=\mathbf{9 7}$ \\
\hline Age (years), mean (SD) & $35.0($ I0.0) \\
Gender (male) (\%) & 72.0 \\
Age at onset (years), mean (SD) & $22.0(8.0)$ \\
Married or cohabiting (\%) & 5.1 \\
Number of hospitalizations (median) (SD) & $3.0(3.7)$ \\
Participating in psychoeducational programs (\%) & 46.9 \\
CGI-S score (mean) (SD) & $3.6(1.3)$ \\
PANSS total score (mean) (SD) & $65.0(21.4)$ \\
SWN-K total score (mean) (SD) & $83.5(14.0)$ \\
\hline
\end{tabular}

Abbreviations: CGI-S, Clinical Global Impression - Severity scale; PANSS, Positive and Negative Syndrome Scale; SWN-K, Subjective Well-being under Neuroleptic scale - short version. 
Table 2 Spearman's rank correlations between SWN-K and SF-36 domains

\begin{tabular}{|c|c|c|c|c|c|c|c|c|}
\hline & \multicolumn{8}{|c|}{ SF-36 domains } \\
\hline & $\begin{array}{l}\text { Physical } \\
\text { functioning }\end{array}$ & $\begin{array}{l}\text { General } \\
\text { health }\end{array}$ & Vitality & $\begin{array}{l}\text { Mental } \\
\text { health }\end{array}$ & $\begin{array}{l}\text { Role } \\
\text { physical }\end{array}$ & $\begin{array}{l}\text { Role } \\
\text { emotional }\end{array}$ & $\begin{array}{l}\text { Social } \\
\text { functioning }\end{array}$ & $\begin{array}{l}\text { Bodily } \\
\text { pain }\end{array}$ \\
\hline SWN-K total score & $0.50 * * *$ & $0.53^{* * *}$ & $0.54 * * *$ & $0.60 * * *$ & $0.52 * * *$ & $0.52^{* * *}$ & $0.49 * * *$ & $0.25^{*}$ \\
\hline Mental functioning & $0.4 I^{* * * *}$ & $0.46 * * *$ & $0.48^{* * * *}$ & $0.50 * * *$ & $0.41^{* * *}$ & $0.45^{* * *}$ & $0.41^{* * *}$ & 0.20 \\
\hline Social integration & $0.43^{* * *}$ & $0.38^{* * * *}$ & $0.39 * * *$ & $0.45 * * *$ & $0.39 * * *$ & $0.48^{* * *}$ & $0.48^{* * *}$ & 0.10 \\
\hline Emotional regulation & $0.37 * * *$ & $0.39 * * *$ & $0.44 * * *$ & $0.46 * * *$ & $0.31 * *$ & $0.33^{* * *}$ & $0.23 *$ & 0.11 \\
\hline Physical functioning & $0.44^{* * *}$ & $0.50 * * *$ & $0.46 * * *$ & $0.60 * * *$ & $0.5 I^{* * *}$ & $0.40 * * *$ & $0.37^{* * *}$ & $0.25^{*}$ \\
\hline Self-control & $0.28 * *$ & $0.34 * * *$ & $0.4 I^{* * *}$ & $0.39 * * *$ & $0.43 * * *$ & $0.40 * * *$ & $0.38^{* * * *}$ & 0.19 \\
\hline
\end{tabular}

Notes: $* p<0.05 ; * * p<0.01 ; * * * p<0.001$.

Abbreviations: SWN-K, Subjective Well-being under Neuroleptic scale - short version; SF-36, Short Form - 36 Health Survey.

patients' perspective. Patients typically rate their utilities much higher than the general public or proxies, while physicians tend to give the lowest ratings. ${ }^{16}$ Therefore, more specific tools in terms of health-related quality of life are still needed. ${ }^{17,18}$

The positive but nevertheless moderate correlations noted between a specific well-being scale, the SWN-K, and a generic quality of life scale, such as the SF-36, support the inclusion of diagnosis-specific instruments for outcome assessment in patients with schizophrenia.

\section{Disclosure}

This study was sponsored by AstraZeneca Spain. Jorge Maurino and Luis Cordero are employees of AstraZeneca.

\section{References}

1. Burns T. Evolution of outcome measures in schizophrenia. $\mathrm{Br} J$ Psychiatry Suppl. 2007;50:s1-s6.

2. König HH, Roick C, Angermeyer MC. Validity of the EQ-5D in assessing and valuing health status in patients with schizophrenic, schizotypal or delusional disorders. Eur Psychiatry. 2007;22:177-187.

3. Alonso J, Prieto L, Antó JM. The Spanish version of the SF-36 Health Survey (SF-36 health questionnaire): an instrument for measuring clinical results. Med Clin (Barc). 1995;104(20):771-776.

4. Van Lente E, Barry MM, Molcho M, et al. Measuring population mental health and social well-being. Int J Public Health. 2011. [Epub ahead of print.]

5. World Health Organization. Mental Health Action Plan for Europe. Facing the Challenges, Building Solutions. Geneva, Switzerland: World Health Organization, 2005.

6. Schennach-Wolff R, Jäger M, Obermeier M, et al. Quality of life and subjective well-being in schizophrenia and schizophrenia spectrum disorders: valid predictors of symptomatic response and remission? World J Biol Psychiatry. 2010;11(5):729-738.
7. Naber D, Moritz S, Lambert M, et al. Improvement of schizophrenic patients' subjective well-being under atypical antipsychotic drugs. Schizophr Res. 2001;50(1-2):79-88.

8. Sanjuan J, Haro JM, Maurino J, et al. Validation of the Spanish version of the Subjective Well-being under Neuroleptic Scale (SWN-K) in patients with schizophrenia. Med Clin (Barc). 2011. [Epub ahead of print.]

9. Vothknecht S, Schoevers RA, de Haan L. Subjective well-being in schizophrenia as measured with the Subjective Well-Being under Neuroleptic Treatment scale: a review. Aust N Z J Psychiatry. 2011; 45(3):182-192.

10. Pukrop R, Schleak V, Moller-Leimkhuler AM, et al. Reliability and validity of Quality of Life assessed by the Short-Form 36 and the Modular System for Quality of Life in patients with schizophrenia and patients with depression. Psychiatry Res. 2003;119(1-2):63-79.

11. Wilke RJ, Burke LB, Erickson P. Measuring treatment impact: a review of patient-reported outcomes and other efficacy endpoints in approved product labels. Control Clin Trials. 2004;25(6):535-552.

12. McCabe R, Saidi M, Priebe S. Patient-reported outcomes in schizophrenia. Br J Psychiatry Suppl. 2007;(50):S21-S28.

13. Montejo AL, Correas Lauffer J, Cuervo J, et al. Validation of a specific measure of health-related quality of life in patients with schizophrenia and bipolar disorder: the 'Tolerability and Quality of Life' (TOOL) questionnaire. Annals Gen Psychiatry. 2011;10:6.

14. Mauriño J, Sanjuán J, Haro JM, Díez T, Ballesteros J. Impact of depressive symptoms on subjective well-being: the importance of patient-reported outcomes in schizophrenia. Patient Prefer Adherence. 2011;5:471-474.

15. Rocca P, Giugiario M, Montemagni C, Rigazzi C, Rocca G, Bogetto F. Quality of life and psychopathology during the course of schizophrenia. Compr Psychiatry. 2009;50(6):542-548.

16. Lenert LA, Ziegler J, Lee T, Sommi R, Mahmoud R. Differences in health values among patients, family members, and providers for outcomes in schizophrenia. Med Care. 2000;38(10):1011-1021.

17. Papaioannou D, Brazier J, Parry G. How valid and responsive are generic health status measures, such as EQ-5D and SF-36, in schizophrenia? A systematic review. Value Health. 2011;14(6):907-920.

18. Cuervo J, Rebollo P, Maurino J, Cordero L, Castejón N. Estimating utilities in schizophrenic and bipolar patients from disease-specific or generic instruments assessing patients' health states: Where are the differences? Value Health. 2011;14(7):A301.
Patient Preference and Adherence

\section{Publish your work in this journal}

Patient Preference and Adherence is an international, peer-reviewed, open access journal focusing on the growing importance of patient preference and adherence throughout the therapeutic continuum. Patient satisfaction, acceptability, quality of life, compliance, persistence and their role in developing new therapeutic modalities and compounds to

\section{Dovepress}

optimize clinical outcomes for existing disease states are major areas of interest. This journal has been accepted for indexing on PubMed Central. The manuscript management system is completely online and includes a very quick and fair peer-review system. Visit http://www.dovepress.com/ testimonials.php to read real quotes from published authors. 